with the International Younger Chemists Network, which is doing a terrific job and constitutes not only an opportunity but a priority for IUPAC.

But among all my priorities for this biennium, I want to highlight IUPAC Digital. Under this label, we include a series of actions that we are conducting at IUPAC to lead the digital chemistry space. This ranges from the creation of a chemical nomenclature for machines, namely the International Chemical Identifier $(\operatorname{InCh} \mid)$, to the adoption of the FAIR principles to ensure that all chemical data is Findable, Accessible, Interoperable, and Reusable. It became very clear during our last General Assembly, which had a session entirely devoted to IUPAC Digital that this is the way to go so IUPAC will keep leading the global chemistry community during the next decades, as most of the chemical information and data is now contained, stored, and shared in bits, not in paper. On this note, the digitalization of our Gold Book represents a unique opportunity to make all our content not only more accessible, but also more relevant, impactful, and useful. Finally, I want to bring here some of the conclusions of our recent World Chemistry Leadership Meeting that under the title "The Future of Chemistry in the World of Al" provided us with a clear and compelling vision for the future of IUPAC. This two-day online meeting, masterfully coordinated by
Chris Ober was a clear call to lead in this emerging field, which is already having a profound impact on chemistry discovery.

We are living in a time of uncertainty and profound changes, but also of great opportunities. Chemistry in general and IUPAC, in particular, are especially well-positioned to contribute to proving the solutions we need so urgently. I know I count on all of you to create an agile, effective, and inspiring organization, and to continue being the international community of chemists, widely recognized by its reputation, independence, and high standards. It will not be an easy task, that is for sure, but it is a challenge worth pursuing.

Javier García-Martínez <j.garcia@ua.es> is a Professor of Inorganic Chemistry and Director of the Molecular Nanotechnology Laboratory of the University of Alicante where he leads an international team working on the synthesis and application of nanostructured materials for the production of chemicals and energy. Javier is IUPAC President since January 2022. Previously, he served as Vice President and member of the Executive Committee, and as Titular Member and Vice-President of the Inorganic Chemistry Division.

*For a list of the actions taken at the IUPAC Council, held Virtual last August during the General Assembly, see https://iupac.org/ actions-taken-at-iupac-council-virtual-2021/

\section{Ethics, Diversity, Equity and Inclusion}

ome National Adhering Organizations or other organizations affiliated with IUPAC have in place committees or reference groups that address issues of ethics or diversity and inclusion. There are numerous womens' chemistry groups worldwide, many linked to the IUPAC Global Womens Breakfast series, and emerging chemists' groups, including the International Younger Chemists Network (IYCN). Specialist groupings include those for chemists of color, for less-able bodied chemists, or from LGBTQ communities. Each of these groupings requires our recognition, respect, and support. IUPAC is in the unique and privileged position to deliver global leadership on their behalf. There are still chemistry communities globally where the principles of equity are less well recognized, and IUPAC can provide support through networking and informal education or advice.

In August 2021, the 51st Council of IUPAC approved the formation of a Standing Committee on Ethics, Diversity, Equity and Inclusion (CEDEI). Plans for this newly established Standing Committee include providing guidelines for diversity and inclusiveness at IUPAC conferences, for editorial board memberships, task group memberships, and on selection panels (e.g. IUPAC awards). The role of CEDEI is outlined in the committee's terms of reference (see below).

IUPAC has a global base of members who are guided by the set of core values and behaviours identified in its strategic plan. Where an incident or behaviour inconsistent with these values is alleged, initial investigation should occur at the same level and with the people implicated involved, and only those incidents/behaviours unable to be resolved should be forarded, and in complete confidence, to CEDEl.

The current terms of reference for CEDEI are:

1. To provide independent advice to the President, Executive Committee, Executive Director, other Standing Committees, Divisions, and Commissions on matters relating to ethics, diversity, equity, and inclusion within the policies, business, and 
